\title{
Periodismo regional y conflictos sociales. Análisis de las opiniones de los diarios Correo y Los Andes de Puno (Perú) durante el
} conflicto social del "Aimarazo" (2011)*

\author{
Regional journalism and social conflicts. Analysis of the opinions \\ of the newspapers Correo and Los Andes from Puno (Perú) \\ during the social conflict of "Aimarazo" (2011)
}

Miguel Angulo Giraldo Magíster en Estudios Latinoamericanos de la Universidad Federal de Integración Latinoamericana (UNILA), Brasil.

Correo electrónico: angulo.runa@gmail.com

Artículo de investigación

DOI: http://dx.doi.org/10.15332/s2339-3688.2017.0001.01

Fecha de recepción: Mayo 15 de 2017 • Fecha de aceptación: Agosto 16 de 2017

* Este artículo es una síntesis acompañada de reflexiones a partir de una investigación realizada por el autor para su tesis de Licenciatura en Comunicación Social en la Universidad Nacional Mayor de San Marcos, que puede ser consultada en: http://cybertesis.unmsm.edu.pe/bitstream/cybertesis/4676/1/Angulo_gm.pdf

También, es parte de la ponencia presentada en la Universidad Santo Tomás en el IV Congreso Internacional de Comunicación Social para la Paz, realizado en octubre de 2015 bajo el título: "Periodismo regional y conflictos sociales. Análisis de las opiniones de los diarios Correo y Los Andes de Puno (Perú) durante el conflicto social del Aimarazo" (2011). 


\title{
Resumen
}

Este artículo reflexiona sobre la labor de dos medios de comunicación regionales, los diarios Correo y Los Andes, respecto al conflicto social del "Aimarazo" (2011), ocurrido en el departamento de Puno (Perú). Se analizan tres cuestiones: los actores y temas mencionados en los artículos de opinión de ambos diarios, los enfoques o los frames periodísticos utilizados en estos textos y las identificaciones ideológicas de los editores de ambos diarios sobre el conflicto estudiado.

En el contexto del "Aimarazo", ambos medios repercutieron en la transformación del conflicto a través de la representación e interpretación de los acontecimientos: se señalaron causas y responsabilidades, se agudizaron las contradicciones y las oposiciones mediante una polarización (víctima-victimario) entre grupos sociales y, finalmente, se legitimaron y deslegitimaron ciertas acciones con base a identificaciones de estos medios con los grupos sociales contrapuestos.

Palabras clave: conflicto social, identidad, frames periodísticos, ideología, prensa gráfica.

\begin{abstract}
This article reflects on the work of two regional mass media newspapers, Correo and Los Andes, about the social conflicts of "Aimarazo" (2011) that had place in the department of Puno (Perú). Three issues are analyzed: the actors and the topics mentioned in the articles of opinion of both newspapers, the journalistic frames used in the texts, and the ideological identifications of the editors of both newspapers about this conflict.

In the context of the "Aimarazo", both media had a repercussion on the transformation of the conflict through the representation and the interpretation of the events: causes and responsibilities were pointed out, contradictions and oppositions were sharpened by a polarization (victim - victimizer) between social groups and, finally, some actions were legitimized and discredited based on ideological identifications of these mass media with the opposing social group.
\end{abstract}

Keywords: Social conflict, identity, journalistic frames, ideology, media. 


\section{INTRODUCCIÓN}

Durante el gobierno de Alejandro Toledo (2001-2006) se impulsó el proyecto de descentralización de los gobiernos locales. A través de la Ley n. ${ }^{\circ} 27.783$ se buscó el desarrollo integral armónico y sostenible del país, mediante la integración regional y la constitución de macro regiones. Además, en el 2002 se creó el Consejo Nacional de Descentralización - CND, con el fin de promover que las regiones tengan un poder de acción propio sin depender necesariamente de Lima (capital peruana).

El denominado "shock descentralizador" (Decreto Supremo 068-2006-PCM) da inicio a la segunda etapa del proceso de descentralización, el cual cobra mayor importancia a partir de las reuniones que llevan a cabo los propios gobiernos regionales en su afán por articularse y dar solución a los problemas de sus regiones y la gestión de sus recursos: se adscribe a la antigua CND dentro de la Secretaría de Descentralización (SD-PCM) articulada a la Presidencia del Consejo de Ministros PCM; y nacen la Asamblea Nacional de Gobiernos Regionales - ANGR, la Junta de Coordinación Interregional - JCI y las mancomunidades municipales.

El proceso de descentralización ha permitido que los gobiernos regionales y locales puedan gestionar sus propios recursos a partir de sus presupuestos participativos con sus comunidades e integrantes. Mas, pasados los años, aún muchas regiones tienen inconvenientes para dar solución a sus problemáticas locales y articular acciones en pro de su desarrollo. "Se ha estancado la transferencia y se han comenzado a producir soluciones sectoriales para resolver la falta de coordinación con los gobiernos regionales, lo que en lugar de profundizar la descentralización ha significado retroceder en ella" (Congreso de la República del Perú, 2013, p. 14).

Sin embargo, el proceso de descentralización ha generado también que las regiones se vean a ellas mismas a partir de sus procesos de participación. De esta forma, en primer lugar, fue la agenda política local la que cobró una mayor importancia.

En este terreno, para noviembre del 2002, se llevaron a cabo las primeras elecciones regionales en las 25 regiones del Perú. En el caso de Puno, una de las regiones 
con mayores postulantes al cargo (7 en total), ganó la elección David Jiménez, del Movimiento por la Autonomía Regional Quechua y Aimara - MARQA.

El proceso de descentralización peruano que permite la creación de los gobiernos regionales en los 24 departamentos del Perú y la provincia constitucional del Callao, invita a mirar en mayor detalle estos espacios desde una perspectiva local, observando los procesos que los involucran y la forma en la que sus medios locales narran sus dinámicas propias.

Según el Instituto Nacional de Estadística e Informática - INEI (2016), la región Puno, escenario de nuestro estudio, es la quinta con mayor cantidad de habitantes en el Perú (la población del Perú para 2016, según INEI, fue de 31'488.625) con 1’429.098 pobladores. Su población (Compañía Peruana de Estudios de Mercados y Opinión Pública, 2016b) convive entre el espacio urbano (54.5\%) y el mundo rural $(45.5 \%)$.

La presencia de los gobiernos regionales impulsa una mayor participación en el escenario político y mediático. Esa relación se refleja en que el segundo presidente regional de Puno, Hernán Fuentes, quien ganó las elecciones para el periodo 2006-2010 al representar al movimiento político "Avanza País”, fuera un periodista destacado de la región y conocido en Puno por sus declaraciones políticas a favor de los derechos indígenas en su programa de Radio Perú (emisora ubicada en Juliaca).

Igualmente, Mauricio Rodríguez asume la presidencia del gobierno regional de Puno en 2011 y su principal labor era como conductor de un espacio radial en la segunda radio más importante de la región: Radio Pachamama.

Vale destacar que, según un estudio del Consejo Consultivo de Radio y Televisión (Concortv, 2015), en el Perú el 75.2\% de peruanos lee diarios entre semana, siendo el tercer medio más consumido. Sin embargo, Puno es la región que le dedica más tiempo al consumo de medios de comunicación (13 horas y media) a comparación del promedio del Perú (11 horas) (Concortv, 2011). 
Este dato es importante, puesto que la lectoría de los periódicos depende de la capacidad de lectura de los ciudadanos, es decir, de tasas cada vez más altas de alfabetización. En el Perú, según INEI (2016), la tasa de analfabetismo es de 6\%, mientras que en Puno es de $9.4 \%$.

En el caso de la prensa puneńa, esta empieza oficialmente con El Correo de Puno en 1826, La Voz de Puno en 1828, y el actual decano de la prensa puneńa, Los Andes de 1928. Actualmente (mayo de 2017), solo tres diarios regionales producen contenidos desde Puno: Los Andes, Correo de Puno (aparecido en 1992) y Sin Fronteras (aparecido en 2014). Es en la capital de Puno donde los dos únicos diarios locales que analizaremos tienen sus centros de operaciones, por lo cual el mayor consumo de prensa en el altiplano peruano se registra entre personas de la ciudad con posibilidades económicas para comprar diarios o que acceden a ellos de manera común.

Según el índice de lectoría de la Compañía Peruana de Estudios de Mercado y Opinión Pública (2016a), Correo es el segundo diario puneño más leído en la región con 29.600 lectores en promedio. Mientras que Los Andes, con un tiraje mucho menor, es el tercer diario con mayores lectores en el género de diarios de opinión (Empresa Periodística Nacional S. A., 2012).

Oyarce (2013, p. 81) recuerda que los medios de comunicación puneños "se han constituido en los escenarios de la política y más aún, se han convertido en los constructores de la agenda pública dada su legitimación en el imaginario altiplánico".

Así como su relación con la política, el escenario mediático puneño tiene como uno de sus temas principales a los conflictos sociales, puesto que esta región muestra una alta tasa de conflictividad social. Desde enero de 2010, y durante los últimos siete años, Puno se ha mantenido entre las tres regiones con mayor cantidad de conflictos (en una sola región) en los reportes mensuales de la Defensoría del Pueblo y lidera este reporte como la región con más conflictos sociales durante siete meses de 2011 (periodo de tiempo del conflicto del "Aimarazo") como se destaca en la siguiente tabla: 
Campos en Ciencias Sociales

Las miradas de los conflictos desde las Ciencias Sociales

Tabla 1. Presencia de la región Puno en el informe de conflicto sociales mensuales

\begin{tabular}{|c|c|c|}
\hline Año & $\begin{array}{l}\text { Posición de Puno en el } \\
\text { ranking de regiones con mayor } \\
\text { cantidad de conflictos }\end{array}$ & $\begin{array}{l}\text { Cantidad de meses por ańo en } \\
\text { que figuró en esa posición }\end{array}$ \\
\hline \multirow{3}{*}{2010} & $1 .^{\circ}$ & 6 \\
\hline & $2 .^{\circ}$ & 5 \\
\hline & $3 .^{\circ}$ & 1 \\
\hline \multirow{2}{*}{2011} & $1 .^{\circ}$ & 7 \\
\hline & $2 .^{\circ}$ & 5 \\
\hline \multirow{2}{*}{2012} & $1 .^{\circ}$ & 2 \\
\hline & $2 .^{\circ}$ & 10 \\
\hline 2013 & $3 .^{\circ}$ & 12 \\
\hline 2014 & $3 .^{\circ}$ & 12 \\
\hline \multirow{2}{*}{2015} & $2 .^{\circ}$ & 2 \\
\hline & $3 .^{\circ}$ & 10 \\
\hline 2016 & $3 .^{\circ}$ & 9 \\
\hline \multirow{3}{*}{ Total } & $1 .^{\circ}$ & 15 \\
\hline & $2 .^{\circ}$ & 20 \\
\hline & $3 .^{\circ}$ & 25 \\
\hline
\end{tabular}

Fuente: Defensoría del Pueblo 2010, 2011, 2012, 2013, 2014, 2015 y 2016

Las tomas de carreteras, paralizaciones y protestas son parte de un entorno donde se hace evidente el choque entre las políticas locales, regionales y del gobierno central frente a las necesidades, los intereses y las propias cosmologías de las comunidades indígenas de las diversas localidades de Puno (quechuas y aimaras, principalmente).

Pero, ¿por qué es importante la influencia de la prensa en un escenario altamente conflictivo? La importancia guarda relación con las representaciones sociales e interpretaciones de la realidad que los medios locales hacen de cada uno de los actores participantes, la forma como configuran su presencia en los medios y su 
reconocimiento como parte del escenario local. En este sentido, Manuel Martín Serrano (2011) destaca que el contenido de los medios de comunicación "propone representaciones del tiempo, del espacio y de lo que acontece" (p. 6). Es decir, la conciencia colectiva se acerca parcialmente a la realidad social a partir de lo que se narra en los medios locales, ya que el contenido de los medios "logra que nuestra conciencia se historice, $[\ldots]$ que encuadre el conocimiento de la realidad en modelos históricamente determinados" (p. 6).

Por ello, este estudio busca presentar un análisis de dos diarios (Los Andes y Correo de Puno) que contribuya a visibilizar lo enunciado a partir de tres puntos: los actores y temas mencionados en los artículos de opinión de ambos diarios, los enfoques o los frames periodísticos utilizados en estos textos y las identificaciones ideológicas de los editores de ambos diarios respecto al conflicto estudiado.

Como antecedentes de nuestro estudio, queremos resaltar solo cinco estudios que pueden ayudar a profundizar en futuras investigaciones. En el caso internacional, dos colombianos y uno argentino nos parecen resaltantes. El realizado por Bonilla y Tamayo (2013) denominado Medios, periodismo y conflicto armado, en el cual se analiza la cobertura del conflicto armado interno colombiano entre 2002 y 2012 a partir de la búsqueda y recolección de textos, artículos, libros, informes, ponencias y memorias de eventos directamente relacionados con las problemáticas de los medios de comunicación y el conflicto armado con el análisis final de 89 documentos. Medios, audiencias y conflicto armado. Representaciones sociales en comunidades de interpretación y medios informativos, realizado por Valencia y Barón (2001) del Centro de Investigación y Educación Popular - CINEP, el cual analiza tres representaciones sobre el conflicto armado colombiano: las de las comunidades de interpretación, las de los periódicos y las mediatizadas que construyen los medios y consumen las comunidades. Finalmente, Representaciones del conflicto y medios masivos: la pueblada de Salta en noviembre de 2000 a través de Clarín y El Tribuno (2014), en el que se analizan un total de 80 noticias publicadas en ambos medios y que concluye que "persisten indicadores de criminalización y judicialización de la protesta social; condicionada, claro está, por el carácter sociopolítico de los sujetos que la llevan a cabo y por los objetivos que persiguen (Artese y Benclowicz, 2013). 
En el caso peruano, dos estudios son claves para entender nuestro caso de análisis: Los límites de la expansión minera en el Perú (2013), en el cual destaca el capítulo "Concesiones, participación y conflicto social" de Quiñones, Bernaola y Zabaleta (2013), dedicado al "Aimarazo", y el trabajo de Omar Cavero (2014) en Hacia un entendimiento de la conflictividad social: las protestas contra la minería en Puno, 2011, un cuaderno de trabajo que recoge un revisión del rol de la prensa en el mismo conflicto que estudiamos.

\section{El “Aimarazo”}

Uno de los conflictos más fuertes de todo el Perú durante los últimos diez años ocurrió en Puno en el 2011: el "Aimarazo", en el cual se movilizaron más de 9.000 aimaras hacia la ciudad de Puno (capital de la región). Se realizaron marchas y protestas constantes en la ciudad por más de 40 días seguidos y se paralizaron parcialmente las actividades económicas y político-administrativas de la capital.

En términos legales, el conflicto se originó por la emisión del D.S. 083-2007-MEM, en el cual se indica que la empresa minera canadiense Bear Creek Company con sucursal en Perú puede adquirir los territorios ubicados a $50 \mathrm{~km}$ de la frontera con Bolivia en los distritos de Huacullani y Kelluyo (provincia de Chucuito, departamento de Puno).

En estas zonas y desde esa fecha, Bear Creek tenía el derecho para empezar la fase de exploración de la mina Santa Ana, que se ubica en esta zona. La primera reacción en contra del proyecto minero se realiza en el 2008 , cuando saquean el campamento de la empresa, y en el 2011 se ocasionan mayores incidentes:

- El 2 de marzo, 5.000 personas se reúnen en la Plaza de Armas de Desaguadero (Chucuito) y acuerdan rechazar el proyecto minero Santa Ana. Ese día conforman el nuevo Frente de Defensa de los Recursos Naturales de la Zona Sur de Puno (FDRNZS). 
- El 9 de mayo, pobladores aimaras de la zona sur de Puno empiezan la huelga indefinida, tomando carreteras de la zona sur.

- El 23 de mayo, 9.000 pobladores de la zona sur de Puno arriban a la ciudad capital para movilizarse y tomar las calles.

- El 26 de mayo, los protestantes comienzan a lanzar piedras a las sedes de los bancos, las cajas municipales, los locales comerciales, entre otros, siendo los más importantes las afectaciones contra el edificio del Ministerio Público, de la Contraloría General de la República y de la Superintendencia Nacional de Administración Tributaria - SUNAT. El local de Aduanas en la región fue quemado ese día.

- El 20 de junio se deroga el Decreto Supremo que otorgaba el permiso para la explotación del proyecto Santa Ana en la región.

- El 26 de junio se decide levantar la huelga indefinida.

A la fecha (agosto de 2017), el principal dirigente del conflicto social, Walter Aduviri, ha sido sentenciado a siete años de pena privativa de libertad, acusado de ser autor mediato por el delito contra la tranquilidad pública en su forma de disturbios, proferida el Juzgado Penal Colegiado de Puno. Sin embargo, el proceso sigue sin resolución final pues la sentencia ha sido apelada.

Según el informe propalado por el diario Los Andes (2017), la sentencia establece que "existió una organización pasible de dominio de la voluntad, debido a que los aimaras protestaban, tras sostener reuniones a través de formas propias de organización social y comunal, bajo el lema 'agua sí, mina no'. En el caso del acusado Walter Aduviri Calisaya, se evidencia su capacidad de liderazgo basado en un mandato social y cultural determinado; la defensa de los recursos naturales y el respeto a las normas que reconocen el derecho de los pueblos. [...] Asimismo, su dominio sobre las organizaciones se representa en el denominado capital cultural y social". 


\section{MARCO TEÓRICO: CONFLICTO SOCIAL, IDENTIDADES Y MEDIOS DE COMUNICACIÓN}

En este punto, queremos reflexionar sobre las ideas esenciales que generan el sentido de nuestro estudio. Inicialmente, incidimos sobre la idea de conflicto social, la cual según Lewis Coser (1961), quien es autor de Las funciones del conflicto social, "es una forma de socialización” (p. 32), por lo cual ningún grupo puede ser completamente armónico, sino que requiere de la disociación y asociación para existir. Esta convivencia, donde el conflicto se asume como parte esencial del día a día y niega la antifuncionalidad del mismo, pasa a ser un elemento trascendente que permite visibilizar las diferencias de los grupos sociales e individuos en el proceso de socialización.

A partir de lo mencionado, en los últimos años se ha buscado comprender que las respuestas a las disputas derivadas de la conflictividad social no deben entenderse como resoluciones, sino como transformaciones. En ese sentido, Lederach (2007) destaca que el conflicto es una oportunidad para el cambio, puesto que "puede entenderse como el motor del cambio, lo que mantiene las relaciones y las estructuras sociales honestas, vivas y respondiendo dinámicamente a las necesidades, aspiraciones y crecimiento humanos" (p. 13).

En este análisis se debe mencionar el concepto que utiliza la Defensoría del Pueblo del Perú (s.f.) y el mismo que se empleará para el presente estudio. Según la página web esta entidad, el conflicto social es un proceso complejo en el cual "sectores de la sociedad, el Estado y/o las empresas perciben que sus posiciones, intereses, objetivos, valores, creencias o necesidades son contradictorios, creándose una situación que podría derivar en violencia”.

El escenario del conflicto social no solo genera una lucha material, sino que, en ese contexto, los elementos simbólicos permiten la significación y resignificación de los espacios de construcción social, sobre todo de las identidades sociales que se disputan también en los espacios públicos y mediáticos.

Pero, ¿qué entendemos por identidad? Según Marcús (2011), la conceptualización histórica de la identidad tiene tres etapas. Una primera etapa consideraba una idea 
de sujeto donde el individuo con capacidad de acción, razón y consciencia posee una identidad fija e inmutable. Una segunda etapa o vertiente más sociológica, en la que el sujeto es producto de la construcción social con una identidad en construcción por interacción socio-comunicativa. Una última etapa relacionada a un sujeto posmoderno descentralizado, con una identidad en tránsito, fragmentado y compuesto por muchas identidades o espacios identitarios.

Este estudio considera importante situarse en la tercera perspectiva, en la que se dejan de lado las posiciones esencialistas de la identidad para entenderla desde un abordaje estratégico y posicional en un proceso inacabado, constante, de reconstrucción permanente de sus límites y relacional en tanto se reformula constantemente una otredad.

Stuart Hall (2003, en Marcús, 2011) pone énfasis en el discurso como elemento que organiza toda la vida social y considera que las identidades se construyen dentro del discurso y no fuera de él. En ese sentido, "[las identidades] emergen en modalidades concretas de juegos de poder y son más el producto de una diferencia y una exclusión que de lo idéntico" (p. 109).

Al no tener límites, la identificación —utilizaremos este término por conveniencia metodológica - nunca está terminada, sino que está en constante movimiento, excluye e incluye sujeta al juego de la diferenciación. Por ello "entraña un trabajo discursivo, la marcación y ratificación de límites simbólicos, la producción de 'efectos de frontera'. Necesita lo que queda afuera, su exterior constitutivo, para consolidar el proceso" (Hall, 2003, p. 16).

Para clasificar una identificación, este estudio parte del elemento ideológico que da forma a una enunciación discursiva de un "nosotros" que se opone a un "ellos", una estrategia que polariza las acciones positivas de nuestro grupo social y deslegitima las del otro, buscando la satisfacción de los intereses propios.

Esta caracterización ideológica que permite notar en nuestro estudio una identificación debe entenderse como un "conjunto de creencias fácticas y evaluativas — es decir, el 
conocimiento y las opiniones- de un grupo, una clase específica de representaciones mentales (básicas) compartidas por los miembros de grupos firmemente localizadas en las mentes de la gente" (Van Dijk, 1999, p. 71), la cual permite que los grupos sociales organicen sus creencias y pensamientos acerca de la realidad social (bueno o malo, adecuado o inadecuado, etc.) según su propia visión.

La configuración de estas identificaciones pasa por los medios de comunicación, puesto que estos visibilizan e invisibilizan a ciertos actores sociales a partir de los acontecimientos narrados. De esta manera, posibilita que ciertos sectores se reconozcan o no a sí mismos y configuren sus identificaciones como formas de representación pública que aparecen en el contenido de los medios.

Por ello, la prensa se constituye como "responsável pelo sentimento de identidade que nos une para formar uma naçáo, um grupo social e, ao mesmo tempo, nos dá a medida da nossa singularidade, concedendo-nos a ilusáo da unidade e da totalidade" (Coracini, 2003, p. 2). Esta idea de los medios como espacios desde donde se configura la identificación de los actores sociales y de los grupos sociales es destacada por Alsina (1996), quien agrega que los periodistas son "constructores de la realidad de su entorno. Pero, además dan forma de narración a esta realidad y, difundiéndola, la convierten en una realidad pública" (p. 15).

En esa labor de construcción de una realidad pública, los medios de comunicación de masas tienden a construir una realidad aparente (en la que la realidad sería un elemento externo a los productores de la comunicación); además, realidad que es aceptada por los receptores de los mensajes. Este carácter legítimo que adquiere el discurso mediático dentro de la sociedad permite que los periodistas tengan un rol socialmente legitimado, donde el producto mediático construye realidades sociales que se asumen como públicas y, sobre todo, relevantes socialmente.

La labor del medio de comunicación en el conflicto, entonces, resulta resaltante para notar las formas en las que su construcción de la realidad — basado en una interpretación de esta - delimita lo que será narrado, aquello que tendrá relevancia y que será puesto en el escenario mediático para ser reconstruida por los receptores de estos mensajes. 
En esa labor de construcción, vale resaltar no solo el tema que aparece narrado, sino el enfoque o frame periodístico con el que es presentado. Ese proceso de encuadre que realizan los periodistas permite establecer que los hechos son de determinada forma y ocurren bajo ciertas características. Allí, los frames permiten estructurar una noticia de cierta manera.

Así, se toma al frame periodístico como la "idea central organizadora del contenido de las noticias que aporta un contexto mediante un proceso de selección, de énfasis, exclusión y elaboración” (Sadaba, 2007, p. 70).

Para nuestro estudio, las categorías para el análisis de medios desde los frames están relacionados a la propuesta de Mitchell et al. (2000), citada por Macassi (2012, p. 110): frame de confrontación, que visibiliza la disputa o contraposición entre dos o más actores sociales, sin relacionarme necesariamente con el conflicto de la realidad social, pues es un conflicto dentro de los límites del texto; frame de interés humano, que se centra en las afectaciones de un sujeto o grupo por determinadas acciones en el contexto del conflicto, generalmente a partir de un caso, testimonio o declaración del perjudicado; frame de consecuencias económicas y sociales, que permite visibilizar los impactos de los acontecimientos sobre estas áreas; frame de responsabilidad, entendido como la determinación de la culpabilidad de uno de los actores sociales dentro del acontecimiento; y el frame de diálogo, agregado por Macassi (2012), quien considera que un enfoque puede destacar la noticia (en nuestro caso, los artículos de opinión) desde una propuesta de diálogo.

\section{Metodología}

El universo total de notas referidas al conflicto es de aproximadamente 55 notas publicadas entre marzo y agosto de 2011, de las cuales se seleccionaron de manera aleatoria 40 (35 de Los Andes y 5 de Correo. Este último durante el periodo de análisis solo publicaron cinco notas referidas al conflicto social). La revisión es cuantitativa, bajo el análisis de los contenidos; y cualitativa en el punto de la identificación ideológica. 
- Campos en Ciencias Sociales

Las miradas de los conflictos desde las Ciencias Sociales

Figura 1. Periódico Los Andes

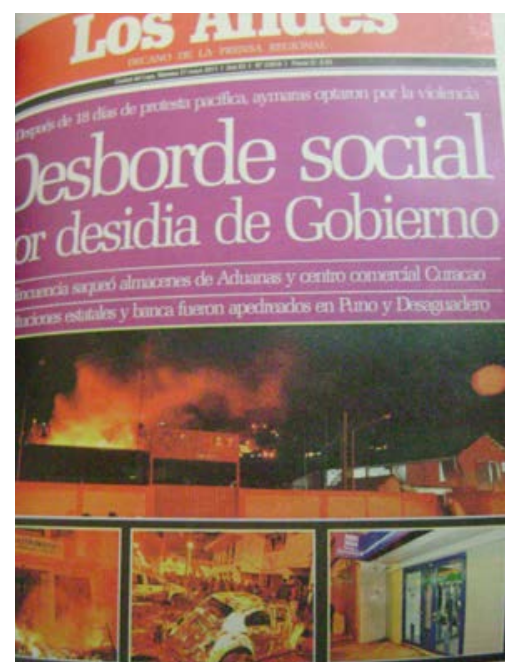

Fuente: Los Andes de Puno del 27 de mayo de 2011

Figura 2. Periódico Correo Puno

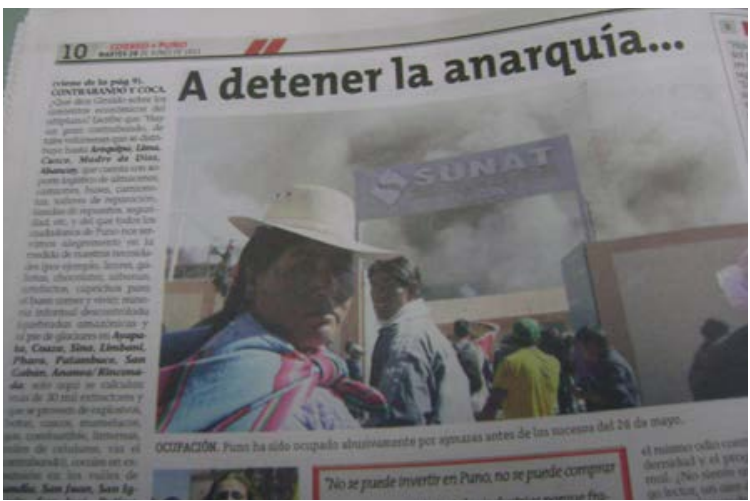

Fuente: Correo Puno del 28 de junio de 2011 
En el primer nivel de análisis se catalogan a los actores aparecidos en las notas, la frecuencia de aparición de los actores principales, la valoración atribuida y finalmente la temática referida de los artículos (categorizamos la idea de tema como la perspectiva textual externa con la que se presenta el "Aimarazo" en el artículo de opinión. En este estudio, puede ser de las siguientes formas: ambiental, política, social, cultural, jurídica, en pro del diálogo u otra).

Tabla 2. Clasificación de actores y temas

\begin{tabular}{|l|l|}
\hline \multirow{5}{*}{ Identificación del actor } & Lista de actores \\
\cline { 2 - 3 } & Frecuencia de aparición de actores \\
\hline \multirow{5}{*}{ Valoración atribuida al actor } & Lista de actores \\
\cline { 2 - 2 } & $\begin{array}{l}\text { Se resaltan más los aspectos positivos del actor/ } \\
\text { acciones/propuestas }\end{array}$ \\
\cline { 2 - 3 } & $\begin{array}{l}\text { Se resaltan más los aspectos negativos del actor/ } \\
\text { acciones/propuestas }\end{array}$ \\
\cline { 2 - 3 } Temática referida & $\begin{array}{l}\text { Se resaltan equilibradamente los aspectos } \\
\text { positivo y negativo }\end{array}$ \\
\hline & Cultural \\
\cline { 2 - 3 } & Ambiental - minera - económica \\
\hline & Judicial \\
\cline { 2 - 2 } & Social \\
\hline & Política \\
\cline { 2 - 2 } & Otro \\
\hline
\end{tabular}

Fuente: elaboración propia

En el segundo nivel, se clasifican los frames periodísticos para notar con qué enfoque fueron presentadas las notas de opinión de los diarios analizados a partir del siguiente esquema: 
Campos en Ciencias Sociales

Las miradas de los conflictos desde las Ciencias Sociales

Tabla 3. Frames periodísticos analizados

\begin{tabular}{|l|l|l|}
\hline \multirow{2}{*}{$\begin{array}{l}\text { De confrontación (resalta } \\
\text { una situación de este tipo) }\end{array}$} & Confrontado 1 (de quien se muestra a favor) & \\
\cline { 2 - 3 } De interés humano & Confrontado 2 (de quien se muestra en contra) & \\
\hline \multirow{2}{*}{ De consecuencias económica } & Actor & Drama \\
\cline { 2 - 3 } & En la economía regional & Motivo de lucha \\
\hline \multirow{2}{*}{$\begin{array}{l}\text { De atribución de } \\
\text { responsabilidad }\end{array}$} & Lista de culpables & \\
\hline \multirow{2}{*}{ De diálogo } & Actores mencionados & \\
\cline { 2 - 3 } & Acuerdos por establecer & \\
\hline Otro & & \\
\hline
\end{tabular}

Fuente: Macassi, 2010, p. 110

En el tercer nivel, se analizan las entrevistas hechas a los editores de los diarios analizados (René Calderón de Los Andes y Hugo Supo de Correo) bajo la perspectiva del análisis de identificación ideológica de Teun Van Dijk (1999), permitiendo evidenciar cómo los sujetos que dirigían los medios y seleccionaban las notas a publicar se identificaron como parte de algunos grupos:

Tabla 4. Distribución del cuadrado ideológico

\begin{tabular}{|l|l|}
\hline \multicolumn{1}{|c|}{ Nosotros } & \multicolumn{1}{c|}{ Ellos } \\
\hline Resaltar nuestras buenas propiedades / acciones & Resaltar sus malas propiedades / acciones \\
\hline Mitigar nuestras malas propiedades / acciones & Mitigar sus buenas propiedades / acciones \\
\hline
\end{tabular}

Fuente: Van Dijk (1999) 


\section{Resultados}

\section{Primer nivel}

En las notas de opinión de Los Andes la mayor frecuencia de aparición la tuvieron los aimaras —aparecidos en 30 de 35 artículos-, el gobierno —en 24 artículos-y los políticos —en 14 artículos—, y se resalta el actor "periodistas", que apareció en 9 artículos. En este diario, los actores con mayores menciones fueron los mismos, solo con el énfasis puesto en que, de los políticos aparecidos, el que mayor presencia tuvo fue el Presidente Regional (PR) de Puno. Los "aimaras" fueron mencionados un total de 159 veces en el diario Los Andes (18\%); el "gobierno", unas 68 veces ( $8 \%)$; y el PR, Mauricio Rodríguez, tuvo 38 menciones (4\%).

En Correo de Puno, la frecuencia de aparición mayor fue de la "población de Puno", en 4 de las 5 columnas; seguido de diversos actores presentes en 3 columnas: el "gobierno", el "Perú", "Aduviri", la "derecha" y la "izquierda". De igual forma, la cantidad de menciones es mayor sobre este mismo actor — la población de Punoquien fue citado 26 veces (17\%), seguido de Alan García — presidente del Perú durante el conflicto - con 10 menciones $(6 \%$ y Ollanta Humala —electo presidente en medio del conflicto- con 9 menciones (6\%).

Queremos destacar aquí que el actor con mayor frecuencia de aparición y mayor cantidad de menciones, los aimaras, fue también el más valorado por ambos diarios. Es decir, quien más adjetivaciones como parte del texto tuvo.

En Los Andes, los "aimaras" fueron los más valorados (35\% del total de actores valorados) y es de destacar que todas las valoraciones positivas sobre ellos — que además fueron hechas únicamente por Los Andes — son referencias directas; es decir, donde el autor afirma las características positivas de los "aimaras". Por otra parte, la mayoría de las valoraciones negativas sobre estos mismos sujetos no fueron directas, sino referidas: citaron a otras personas para destacar los aspectos negativos de los aimaras.

En el caso del diario Correo, el actor con mayor cantidad de valoraciones negativas fueron también los "aimaras" (9); no obstante, a ellos solo se les categorizó de forma 
negativa y siempre con expresiones directas, donde el autor del texto asumía esa adjetivación como propia.

Evidenciamos en este nivel que la identificación con el grupo social (un "nosotros" frente a un "ellos") no solo implica la adjetivación negativa de ese otro grupo social — como Correo_- sino también busca resaltar cómo ese otro grupo social se refiere a nuestro grupo social o al grupo con el que mayor simpatía tenemos — las valoraciones referidas - para poder ser juzgado a partir de esa valoración.

Al notar los temas o las temáticas referidas, se observa que la temática política es la preferida por los columnistas con el $37 \%$ del total de notas analizadas, pero es importante destacar que el conflicto se originó por la defensa de los recursos naturales que iban a hacer afectados por el proyecto Santa Ana, la defensa del lago Titicaca y la prohibición de la minería en la región. Es decir, una motivación, sobre todo ambiental, pero que no es la temática mayoritaria que refieren los autores de los artículos de opinión.

\section{Segundo nivel}

En el caso del diario Los Andes, los frames periodísticos más utilizados fueron: el enfoque de responsabilidad, aparecido en 13 artículos de opinión (37\%); y el enfoque de confrontación, aparecido en 11 artículos de opinión (31\%).

En este diario, la responsabilidad principal del escalamiento del conflicto la tiene el Estado peruano; no obstante, el segundo responsable de los sucesos ocurridos estaba centrado en los medios de comunicación o periodistas: no se culpa al medio o periodista por promover el conflicto, sino que se vinculan los argumentos expresados por ellos como una errónea interpretación de los hechos que no contribuyen a la transformación del conflicto.

Igualmente, en Los Andes, el $91 \%$ de sus notas con enfoque de confrontación se muestra a favor del pueblo o la cultura aimara, lo que es un indicador importante de la posición del diario en pro de una de las partes del conflicto. A ellos se 
oponen, mayoritariamente, los actores relacionados al gobierno central (38\% de las menciones), lo cual genera una oposición primaria: nosotros estamos a favor de los aimaras, quienes están en contra del Estado, por lo cual nosotros estamos también en contra del Estado.

En el caso de Correo, el enfoque de confrontación está presente en dos artículos de opinión (40\%); y el enfoque de consecuencias económicas, que incluye además de consecuencias argumentos económicos del conflicto, está presente en dos artículos de opinión (40\%).

Se debe resaltar que en los frames analizados, el de diálogo solo estuvo presente en un artículo de opinión, lo cual permita notar la carencia de este enfoque para abordar el conflicto. Resaltamos ello, puesto que al notar la importancia del medio de comunicación en el escalamiento del conflicto y en la transformación de este, la poca presencia de la búsqueda de diálogo limita los caminos para una toma adecuada de decisiones.

\section{Tercer nivel}

Tabla 5. Identificación ideológica "ellos" / "nosotros"

\begin{tabular}{|c|c|c|}
\hline & "Nosotros" & "Ellos" \\
\hline $\begin{array}{l}\text { René Calderón } \\
\text { (Editor de Los Andes } \\
\text { durante diciembre } \\
\text { de } 2014 \text {, fecha de } \\
\text { realización de la } \\
\text { entrevista, y editor de } \\
\text { Los Andes durante } \\
\text { el conflicto social del } \\
\text { "Aimarazo"). }\end{array}$ & $\begin{array}{l}\text { "Los aimaras para nosotros } \\
\text { no eran los violentos, } \\
\text { personas que pedían con } \\
\text { justa razón que se respete } \\
\text { el derecho a la consulta. } \\
\text { No fueron tomados como } \\
\text { revoltosos, era gente que } \\
\text { exigía con justicia sus } \\
\text { derechos". }\end{array}$ & $\begin{array}{l}\text { - "El gobierno nacional era visto como } \\
\text { un gobierno débil, siempre se esperaba } \\
\text { que el gobierno tenga una respuesta más } \\
\text { firme, al menos eso se esperaba desde } \\
\text { acá, cuando saquearon Aduanas no pasó } \\
\text { nada, SUNAT y no pasó nada, hasta } \\
\text { ahora no pasa nada, entonces es un } \\
\text { Estado débil, sin respuesta". } \\
\text { - "El gobierno regional tomó una } \\
\text { posición inoportuna, creo que debió } \\
\text { abstenerse de opinar en esta situación, } \\
\text { ser neutral o ponerse de un lado". }\end{array}$ \\
\hline
\end{tabular}




\begin{tabular}{|c|c|c|}
\hline & "Nosotros" & "Ellos" \\
\hline $\begin{array}{l}\text { Hugo Supo } \\
\text { (Editor de Correo } \\
\text { durante diciembre } \\
\text { de } 2014 \text {, fecha } \\
\text { de realización de } \\
\text { la entrevista. No } \\
\text { fue editor durante } \\
\text { el periodo del } \\
\text { conflicto social del } \\
\text { "Aimarazo"). }\end{array}$ & $\begin{array}{l}\text { “Si bien el 'Aimarazo' fue } \\
\text { una explosión de la protesta. } \\
\text { El problema del “Aimarazo" } \\
\text { ha arrastrado un cúmulo de } \\
\text { hechos anteriores, que tiene } \\
\text { que ver con exclusión social, } \\
\text { resentimiento por parte de } \\
\text { las comunidades, con malas } \\
\text { experiencias con la minería, } \\
\text { con malas políticas de no } \\
\text { mostrar minería buena ni } \\
\text { mala, sino la minería solo } \\
\text { como tal”. }\end{array}$ & $\begin{array}{l}\text { - "El Estado no ha actuado } \\
\text { correctamente, ya que no los ha } \\
\text { atendido en el tiempo que debía } \\
\text { preventivamente". } \\
\text { - "El gobierno regional es una entidad } \\
\text { que no sabe manejar conflictos, } \\
\text { inexperta, sin criterios, que no ha } \\
\text { podido liderar todo ese proceso". } \\
\text { - "La empresa ha tratado, pero al } \\
\text { final no ha conseguido dialogar. Ha } \\
\text { cometido errores al denunciar a los } \\
\text { dirigentes por los hechos en el } 2007 \text { y } \\
\text { eso ha generado resentimiento guardado } \\
\text { hasta ahora". } \\
\text { - "El gobierno regional era visto como } \\
\text { una entidad que no sabe manejar } \\
\text { conflictos, una gestión reciente, } \\
\text { inexperta, ineficiente, sin criterio". } \\
\text { - "El presidente regional, que ha podido } \\
\text { en algún momento liderar todo el } \\
\text { proceso, no ha sabido canalizar todas las } \\
\text { demandas. En determinado momento } \\
\text { ha chocado, ha insultado a la gente, ha } \\
\text { tenido el desatino de hablar contra los } \\
\text { propios aimaras, entonces la gente no se } \\
\text { ha sentido representada por él”. }\end{array}$ \\
\hline
\end{tabular}

Fuente: Supo, H., comunicación personal, 5 de diciembre de 2014 y Calderón, R., comunicación personal, 5 de diciembre de 2014

Como se observa, las comunidades aimaras fueron destacadas (por parte de los entrevistados de ambos diarios) como los protestantes, pero que realizaban acciones con justa razón. Igualmente, el Estado y el gobierno regional fueron los actores a quienes se opusieron los aimaras. Es decir, representaron un "ellos" frente a quienes las comunidades se enfrentaron durante el conflicto. 


\section{ConClusiones}

A partir del estudio de 40 artículos de opinión de los diarios Correo y Los Andes de Puno referidos al conflicto social del "Aimarazo" (2011), cuyo objetivo estuvo centrado en notar los actores, temas, frames periodísticos e identificación ideológica de los editores de ambos medios mediante análisis cuantitativos y cualitativos, concluyo:

Es importante notar la alta presencia de los sujetos locales en los diarios (población aimara y población puneña), generalmente en oposición al gobierno central o gobierno regional, siendo los actores de quienes más se habla. Esta oposición primaria permite evidenciar la forma como se enfocaron los artículos de opinión durante el conflicto.

La peculiar invisibilidad de la empresa, incluso su escasa mención por parte de los editores de los diarios analizados, da cuenta de que los actores locales no se oponen a ella de manera evidente, y que para los propios analistas la empresa era un actor indirecto del conflicto. Por eso, se destaca una alta presencia de la temática política, la que guarda relación con políticas públicas en torno a la minería y otras reivindicaciones culturales o sociales. Es decir, el conflicto en los medios regionales analizados no estuvo centrado en el caso concreto, sino en ausencias estatales, reclamos sociales y luchas de un grupo étnico determinado que, a raíz de lo ocurrido con el proyecto minero, pudieron ser expresados bajo otras condiciones.

Por otro lado, se observa la escasa búsqueda del diálogo en los artículos, lo cual llama la atención sobre las funciones de los medios de comunicación durante el conflicto, sobre todo en un contexto local, donde prima un ambiente con intereses contrapuestos que buscan visibilizarse para ser atendidos.

Finalmente, la forma como los editores y el columnista de opinión miran el conflicto permite notar la oposición ideológica de los aimaras ("nosotros") frente a las entidades del gobierno ("ellos"), identificando como cercanos con los primeros y viendo a los 
últimos como el origen del problema, como los que generaron el conflicto al no atender las demandas existentes.

La identidad, construida y reconstruida a partir de las posiciones y los elementos narrativos planteados durante un conflicto social, nos invita a repensar dos cuestiones. La primera apunta a la influencia de las narraciones que los medios construyen respecto del escenario propio del conflicto en la transformación de este o su agudización. En ese sentido, como determina las formas en las que se debe interpretar el propio conflicto por parte de las autoridades, de los sujetos implicados y de la opinión pública. Un segundo punto está referido a las posiciones de los medios en un contexto conflictivo; es decir, muchas veces en favor de un sector social y étnico que en la estructura social está siendo afectado por las grandes políticas estatales, y que es la menos favorecida materialmente. Esa posición puede ser interpretada no como una interferencia política sino como una posibilidad para visibilizar una agenda, en muchos casos, ignorada por el gobierno y las entidades públicas, que permita tender puentes para mediar hacia el diálogo y la transformación del conflicto.

\section{REFERENCIAS BIBLIOGRÁFICAS}

Alsina, M. R. (1996). La construcción de la noticia. Barcelona: Ediciones Paidós Ibérica.

Artese, M., y Benclowicz, J. (2013). Representaciones del conflicto y medios masivos: la pueblada de Salta en noviembre de 2000 a través del Clarín y El Tribuno. Revista Estudios Sociales Contemporáneos, (9), 113-127.

Bonilla, J., y Tamayo, C. (2013). Medios, periodismo y conflicto armado. La agenda investigativa sobre la cobertura informativa del conflicto armado en Colombia, 2002-2012. Medellín y Cartagena: Fundación para el Nuevo Periodismo Iberoamericano. Recuperado de http:// www.academia.edu/11712079/Medios_periodismo_y_conflicto_armado_la_agenda_ investigativa_sobre_la_cobertura_del_conflicto_armado_en_Colombia_2002-2012 
Cavero, O. (2014). Hacia un entendimiento de la conflictividad social: Las protestas contra la minería en Puno, 2011. Lima: Pontifica Universidad Católica del Perú. Recuperado de http://repositorio.pucp.edu.pe/index/handle/123456789/52655

Congreso de la República del Perú. Comisión de descentralización, regionalización, gobiernos locales y modernización de la gestión del Estado. (2013). Evaluación del proceso de descentralización. A 10 años de su inicio. Lima: Congreso de la República del Perú.

Compañía Peruana de Estudios de Mercados y Opinión Pública. (2016a). Estudio de lectoría de diarios en Lima y 15 principales ciudades. Lima: CPI. Recuperado de http://cpi.pe/ images/upload/paginaweb/archivo/23/LectoriaDiarios_2016.pdf

Compañía Peruana de Estudios de Mercados y Opinión Pública. (2016b). Perú: población 2016. Lima: INEI. Recuperado de http://cpi.com.pe/filestore/mr_201608_01.pdf

Concortv. Consejo Consultivo de Radio y Televisión. (2011). Estudio de actitudes, hábitos y opinión sobre la radio y televisión. Lima: Concortv.

Concortv. Consejo Consultivo de Radio y Televisión. (2015). Consumo radial y televisivo 2015. Lima: Concortv. Recuperado de http://www.concortv.gob.pe/file/2015/resumenestudio-2015.pdf

Coracini, M. (2003). A celebração do outro na constituição da identidade. Organon, 17(35), 201-220.

Coser, L. (1961). Las funciones del conflicto social. México: Fondo de Cultura Económica.

Defensoría del Pueblo. (2013). Decimoséptimo informe anual de la Defensoría del Pueblo. Lima.

Defensoría del Pueblo. (s.f.). Conflictos sociales. Recuperado de https://www.defensoria.gob. pe/temas.php?des=3 
Empresa Periodística Nacional. (2012). Estudio de lectoría de diarios según centros de edición del diario Correo. Lima.

Hall, S. (2003). ¿Quién necesita identidad? En S. Hall y P. Du Gay (Comp.). Cuestiones de identidad cultural. Buenos Aires: Amorrortu Editores.

Instituto Nacional de Estadística e Informática - INEI. (2016). Perú: sintesis estadística 2016. Lima: INEI. Recuperado de http://www2.congreso.gob.pe/sicr/cendocbib/con4_uibd. nsf/04D35E1EEE71C56A0525807900737627/\$FILE/1_pdfsam_1.Inei-libro.pdf

Lederach, J. (2007). Definiendo la transformación del conflicto. Hechos del callejón, 3(26), $11-14$.

Los Andes. (22 de julio de 2017). El contexto de la sentencia del "Aimarazo". Los Andes. Recuperado de http://pe.noticiasol.com/los-andes/el-contexto-de-la-sentencia-del-aimarazo. html

Macassi, S. (2010). Medios y conflictos sociales. Entre el rating y el activismo. Diálogos de la comunicación, (81).

Macassi, S. (2012). El tratamiento informativo según el ciclo de vida de los conflictos socioambientales: un estudio comparativo de tres casos en medios regionales y nacionales. (Tesis de maestría). Lima: Pontifica Universidad Católica del Perú. Recuperado de http://tesis. pucp.edu.pe/repositorio//handle/123456789/4529

Marcús, J. (2011). Apuntes sobre el concepto de identidad. Intersticio: Revista Sociológica de Pensamiento Crítico, 5(1).

Oyarce, J. (2013). Memoria e historias. Radio y poder en el altiplano peruano. Lima: Fondo Editorial de la UNMSM.

Quińones, P., Bernaola, D., y Zabaleta, M. (2013). Concesiones, participación y conflicto social. En J. Torres (Ed.). Los límites de la expansión minera en el Perú. Lima: Asociación Servicios Educativos Rurales. 
Sadaba, T. (2007). Framing: el encuadre de las noticias. El binomio terrorismo - medios. Buenos Aires: La Crujía.

Serrano, M. M. (2011). La mediación de los medios de comunicación. Sociología de la comunicación de masas. México: Escuelas y Autores.

Valencia, M., y Barón, L. (2001). Medios, audiencias y conflicto armado. Representaciones sociales en comunidades de interpretación y medios informativos. Controversia, (178). Bogotá: CINEP. Recuperado de http://biblioteca.clacso.edu.ar/Colombia/cinep/20100922025101/mediosaudienciayconflicto.pdf

Van Dijk, T. (1999). Ideología. Barcelona: Editorial Gedisa. 